\title{
Biofluid Markers for Prodromal Parkinson's Disease: Evidence From a Catecholaminergic Perspective
}

\begin{abstract}
Yannick Vermeiren ${ }^{1,2,3,4 *}$, Yael Hirschberg ${ }^{3,4 t}$, Inge Mertens ${ }^{3,4}$ and Peter P. De Deyn ${ }^{1,2,5 *}$
${ }^{1}$ Laboratory of Neurochemistry and Behavior, Department of Biomedical Sciences, Institute Born-Bunge, University of Antwerp, Antwerp, Belgium, ${ }^{2}$ Department of Neurology and Alzheimer Center, University of Groningen and University Medical Center Groningen (UMCG), Groningen, Netherlands, ${ }^{3}$ Centre for Proteomics (CFP), University of Antwerp, Antwerp, Belgium, ${ }^{4}$ Sustainable Health Department, Flemish Institute for Technological Research (VITO), Mol, Belgium, ${ }^{5}$ Department of Neurology, Memory Clinic of Hospital Network Antwerp (ZNA) Middelheim and Hoge Beuken, Antwerp, Belgium
\end{abstract}

Parkinson's disease (PD) is the most frequent of all Lewy body diseases, a family of progressive neurodegenerative disorders characterized by intra-neuronal cytoplasmic inclusions of $\alpha$-synuclein. Its most defining features are bradykinesia, tremor, rigidity and postural instability. By the time PD manifests with motor signs, $70 \%$ of dopaminergic midbrain neurons are lost, and the disease is already in the middle or late stage. However, there are various non-motor symptoms occurring up to 20 years before the actual parkinsonism that are closely associated with profound deficiency of myocardial noradrenaline content and peripheral sympathetic denervation, as evidenced by neuroimaging experiments in recent years. Additionally, there is an inherent autotoxicity of catecholamines in the neuronal cells in which they are produced, forming toxic catecholaldehyde intermediates that make $\alpha$-synuclein prone to aggregation, initiating a cascade of events that ultimately leads to neuronal death. The etiopathogenesis of PD and related synucleinopathies thus may well be a prototypical example of a catecholamine-regulated neurodegeneration, given that the synucleinopathy in PD spreads in synergy with central and peripheral catecholaminergic dysfunction from the earliest phases onward. That is why catecholamines and their metabolites, precursors, or derivatives in cerebrospinal fluid or plasma could be of particular interest as biomarkers for prodromal and de novo PD. Because there is great demand for such markers, this mini-review summarizes all catecholamine-related studies to date, in addition to providing profound neurochemical evidence on a systemic and cellular level to further emphasize this hypothesis and with emphasis on extracellular vesicles as a novel diagnostic and therapeutic incentive.

Keywords: biomarker, catecholamines, cerebrospinal fluid, DHPG/MHPG, DOPAC, extracellular vesicles, Parkinson's disease, plasma

\section{INTRODUCTION}

Parkinson's disease (PD) is recognized as the second most common neurodegenerative disorder following Alzheimer's disease (AD), with an approximate incidence rate of 10-18 per 100,000 person-years. PD is present in about $1 \%$ of the population over 65 years of age and more than $4-5 \%$ in that over 80 . Age and gender are established risk factors, followed by ethnicity. An 
increase by more than $50 \%$ is expected by 2030 , given the rising life expectancy worldwide $(1,2)$. Generally, PD is diagnosed when bradykinesia occurs alongside rigidity or tremor, so its clinical diagnosis mostly depends on motor findings. On the pathological level, this is when about $50-80 \%$ of the dopaminergic neurons of the substantia nigra pars compacta (SNpc) are lost due to $\alpha$-synuclein deposits, known as Lewy bodies. PD is, therefore, often diagnosed clinically when the synucleinopathy is already advanced. On the other hand, patients frequently report having non-motor symptoms for 10-20 years before the diagnosis (3). These prodromes, defined as "early (non-specific) symptoms or signs which often indicate the onset of a disease before more diagnostically specific signs and symptoms develop," provide a potential temporal window during which disease-modifying therapy, once it becomes available, could be administered to prevent or delay the development and progression of disease. Similarly, researchers and clinicians recognize the need for a clinical diagnosis based on quantifiable measures (i.e., biomarkers) to refine qualitative assessments. Characteristic prodromal symptoms of PD are impaired olfaction (anosmia/hyposmia), constipation, depression, excessive daytime sleepiness, rapid eye movement (REM) sleep behavior disorder (RBD), impaired color vision, mild cognitive impairment, and autonomic dysfunction (e.g., orthostatic hypotension $(\mathrm{OH})$, erectile dysfunction, bladder disturbances) $(1,3)$. From a neurochemical point of view, PD was the first neurodegenerative disease of which the underlying neurochemical abnormality was identified, i.e., striatal depletion of the catecholamine dopamine (DA) (4). This pivotal discovery led to the introduction of the first successful symptomatic treatment with levodopa/carbidopa therapy (5). Almost half a century later, this theory of "central catecholamine deficiency" in PD has expanded considerably, entailing both dopaminergic and noradrenergic neurotransmission deficits, not only in the central but also in the peripheral nervous system.

\section{PERIPHERAL CATECHOLAMINERGIC DEFICIENCY AS NEUROCHEMICAL SUBSTRATE OF PRODROMES IN PD}

A catecholamine is a monoamine neurotransmitter, an organic compound that has a catechol (benzene ring with adjacent hydroxyl groups) and one ("mono") side-chain amine group. Included among catecholamines are DA and (nor)adrenaline [(N)A]. All are derived from the amino acid tyrosine, which is retrieved from dietary sources, as well as synthesis from phenylalanine. Principal metabolites of DA and $(\mathrm{N}) \mathrm{A}$, are 3,4-dihydroxyphenylacetic acid (DOPAC) and homovanillic acid (HVA), and, 3,4-dihydroxyphenylglycol (DHPG) and 3methoxy-4-hydroxyphenylglycol (MHPG). Furthermore, NA is synthesized from DA (6). Catecholamine neurons are relatively rare in the central nervous system, but with abundant afferent and efferent projections. Toxic intraneuronal $\alpha$-synuclein depositions in the brainstem nuclei that produce DA and NA, i.e., SNpc and locus coeruleus (LC), therefore, leads to widespread alterations on both central and peripheral levels.
Interestingly, upregulated NA reuptake in the LC area of early-stage PD patients, compatible with enhanced NA release, has previously been suggested as a compensatory, protective mechanism against degeneration of nigrostriatal dopaminergic projections (7).

Apart from the central depletion of DA in the brain's nigrostriatal system, giving rise to the well-known motor phenomenology, PD is equally characterized by a severe deficiency of NA in the heart (8). Other Lewy body diseases such as pure autonomic failure or dementia with Lewy bodies (DLB) similarly involve decreased myocardial NA content (9). According to Braak's staging concept, nigrostriatal neuropathological lesioning in PD occurs in stage three out of six (10) and imputes early autonomic involvement (11). The LC, the brain's main source of NA, becomes affected by the synucleinopathy in stage two. During stage one, the dorsal motor nucleus of the vagal nerve becomes affected, which has strong connections with the parasympathetic nervous system of the gastrointestinal system and lungs and with the nucleus ambiguous, which partially involves the innervation of the heart via preganglionic parasympathetic neurons (12). Intriguingly, peripheral cardiac sympathetic neurodegeneration occurs even earlier in the disease process and has a significant clinical importance. The cardiac noradrenergic sympathetic deficiency has been associated with cognitive impairment (13), fatigue/exercise intolerance (14, 15), anosmia (16), RBD (17), visual hallucinations (18), falls from neurogenic $\mathrm{OH}$ (19), and decreased survival (20). Gastrointestinal symptoms due to local $\alpha$-synuclein accumulation and as part of enteric neuronal dysfunction also appear well before the onset of motor symptoms (21).

In $\mathrm{PD}, \mathrm{OH}$ is a common prodrome that occurs some years before or concurrent with the clinical motor phase and is associated with sympathetic neurocirculatory failure (22). The loss of sympathetic noradrenergic neurons thus might be assumed, but studies using immunoreactive tyrosine hydroxylase as a marker of myocardial catecholaminergic innervation have noted a $75 \%$ decrease (23), whereas the loss of NA levels is about $95-99 \%(8,9)$. This points to a proportion of inactive/dysfunctional but not completely eradicated residual nerves and may involve abnormalities in vesicular storage of NA, altered enzymes, decreased vesicular uptake via the vesicular monoamine transporter (VMAT) type 2, and, increased vesicular permeability (24). The cardiac sympathetic denervation does not affect cardiac structure or function under resting conditions but creates a failure to increase the myocardial contractility following stimuli that depend on NA release, for instance during exercise, and is linked with generalized fatigue (25). In $\mathrm{AD}$, myocardial sympathetic innervation is unaltered, so cardiac sympathetic neuroimaging can provide a means for improvement of the differential diagnosis between AD and DLB, as was evidenced previously using ${ }^{123}$ I-metaiodobenzylguanidine scintigraphy (26).

Remarkably, neither the severity of noradrenergic sympathetic denervation nor values for measures of other non-motor manifestations seem to be $100 \%$ related to the severity of 
loss of central nigrostriatal dopaminergic neurons $(16,27)$. If compatible with Braak's concept of ascending pathology, such patients with decreased striatal dopaminergic innervation should also have cardiac noradrenergic denervation. In contrast, autonomic dysfunction seems to occur independently of the dopaminergic cell loss that causes the parkinsonian triad of motor symptoms (9).

\section{LOW AND HIGH FUNCTIONAL THRESHOLD SYSTEMS}

The hypothesis of Braak et al. of the ascending and transsynaptically prion-like spreading of $\alpha$-synuclein from peripheral nerves, such as via a nasal or gastric route (28), to the brainstem and midbrain up to higher cortical structures is questioned due to contradictory neurochemical, neuroimaging, and clinical evidence [(9), for review: (29)]. In part, the evidence against the idea of the trans-synaptic spread comes from Tysnes et al. (30), who concluded that the idea of performing full truncal vagotomy in reducing the risk of PD (31) may be too premature. Recently, Engelender and Isacson (29) challenged the theory of Braak et al. and proposed a model based on evidence of parallel degeneration and pathology of the central and peripheral nervous system in PD. Under this alternative, systems reach their individual thresholds for symptoms at different rates. Even though the brainstem, peripheral and autonomic neurons seem more resilient to insults as opposed to dopaminergic midbrain neurons, the threshold for the brainstem and peripheral motor symptoms to become apparent is lower than that for motor symptoms. The key factor in understanding this theory is the greater functional reserve of the dopaminergic midbrain neurons, which are more sensitive but have vast interconnections throughout the midbrain, striatal, pallidal, thalamic, and cortical nuclei, providing extensive compensatory mechanisms and redundancy to allow initiation of movement. This is in contrast to catecholaminergic neurons of the autonomic, peripheral, and enteric nervous systems which interconnect with the brainstem nuclei (29). Various types of inputs to the striatal medium spiny neurons derived from, e.g., cortex (glutamatergic), thalamus (glutamatergic), and even the dorsal raphe nuclei (serotonergic), could compensate for a progressively reduced input of dopaminergic SNpc neurons. Direct and indirect pathways of the striatal system have strong bidirectional interactions. On the other hand, the functional network of the enteric nervous system (cholinergic, noradrenergic) is much less developed, suggesting that enteric neurons would have less functional reserve and thus may elicit constipation as a prodromal symptom. Cardiac autonomic dysfunction (noradrenergic) and RBD due to lesioning of the brainstemreticular activating system (cholinergic, noradrenergic) may develop likewise.

In essence, $70 \%$ loss of sensitive dopaminergic midbrain neurons causes motor symptoms (high threshold), whereas only a $20-30 \%$ reduction in mainly noradrenergic neurons of the brainstem/peripheral/enteric/autonomic nervous system (low threshold) already seems sufficient to elicit non-motor symptoms. In agreement, the difference between the low and high functional threshold system may explain the appearance of prodromes up to 20 years before the onset of the motor symptomatology and supports the notion of an ideal biofluid marker for prodromal PD to potentially be of catecholaminergic origin (Figure 1).

\section{THE CATECHOLAMINE AUTOTOXICITY THEORY: IMPLICATIONS FOR BIOMARKER RESEARCH}

Dopamine spontaneously auto-oxidizes to form neuromelanin, the black pigment that pinpoints the $\mathrm{SNpc}$, and the final product of the DA oxidative pathway. Nigral depigmentation, therefore, likely has a neurochemical basis. In a nutshell, the "catecholaldehyde hypothesis" in PD theorizes that longterm increased buildup of 3,4-dihydroxyphenylacetaldehyde (DOPAL) - the catecholaldehyde of DA-significantly contributes to the death of dopaminergic neurons $(33,34)$. This concept builds on the notion that there is an inherent cytotoxicity of catecholamines and metabolites in the cells in which they are produced [Figure 11 of Goldstein and Sharabi (9)]. The vesicular uptake of cytosolic DA is regulated via VMAT2. Next, DA leaks from the synaptic vesicle into the cytosol, undergoing exocytotic release. DA transporter takes most of the released DA back into the cytosol. However, within the neuron, monoamine oxidase (MAO)-A enzymatically oxidizes DA into an intermittent form, i.e., DOPAL. This reaction yields hydrogen peroxide, which reacts with metal cations to produce extremely harmful hydroxyl radicals. DOPAL can also auto-oxidize, forming DOPAL-quinone, which can be transformed into cysteinylDOPAL. Simultaneously, this reaction produces deleterious reactive oxygen species (ROS). Under physiological conditions, DOPAL is metabolized into DOPAC by aldehyde dehydrogenase (ALDH). In glial cells, DOPAC is further metabolized into HVA by catechol-O-methyltransferase (COMT).

Apart from the enzymatic deamination of cytoplasmic DA into DOPAL, DA itself can also auto-oxidize into DA-Oquinone, producing cysteinyl-DA (cys-DA), (amino)chrome, 5,6-indolequinone, polydopamine, and condensation products (e.g., salsolinol), most of which are toxic for the cellular environment. Finally, from 5,6-indolequinone, neuromelanin is formed and stored.

It seems that enzymatic or spontaneous DA oxidation creates aldehydes (DOPAL), ROS, hydrogen peroxide, and thio-catecholamines (cys-DA/cys-DOPAL) within the neuron. The peculiar tendency of $\alpha$-synuclein to precipitate in dopaminergic neurons can be explained by the fact that DOPAL-quinone can induce oligomerization of $\alpha$-synuclein in the cytoplasm, forming Lewy bodies. Moreover, ROS inhibit ALDH and thus build up cytoplasmic DOPAL, which leads to an imbalanced system.

The same goes for the production of the noradrenergic aldehyde dihydroxyphenylglycolaldehyde (DOPEGAL). DOPEGAL is formed in the sympathoneural cytosol upon 


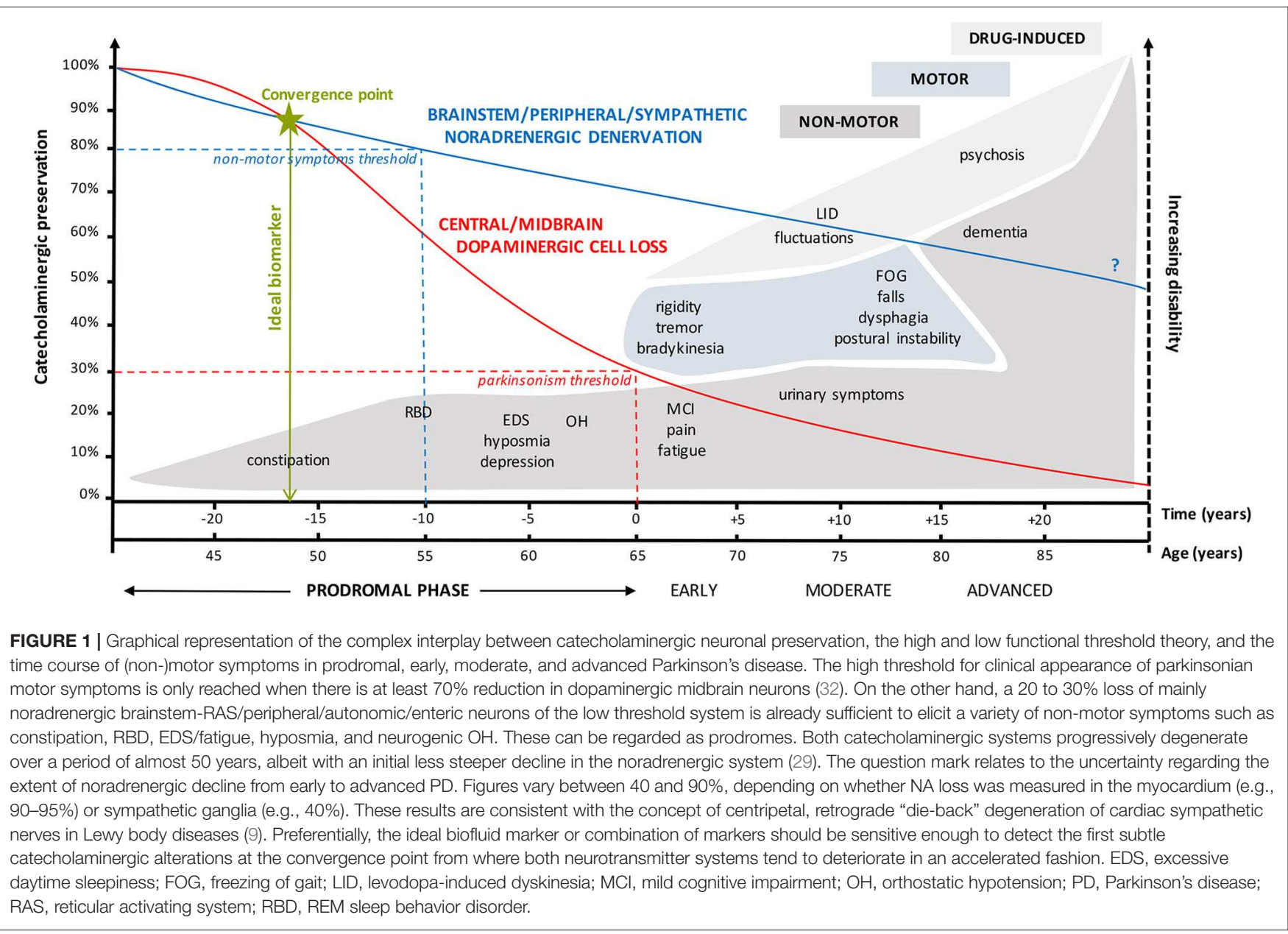

oxidative deamination of NA and undergoes metabolization to form DHPG, mainly via aldehyde/aldose reductase (6). Similar as with DOPAL-induced synucleinopathy in the $\mathrm{SN}$ in $\mathrm{PD}$, the DOPEGAL-promoted formation of tau aggregates in the LC in $\mathrm{AD}$ has recently been demonstrated (35).

Various early alterations within the dopaminergic neuron, such as decreased vesicular sequestration of DA via VMAT2 and decreased DOPAL metabolism by reduced activity of ALDH, are the multifactorial result of genetic predispositions, exposure to environmental toxins, stress, and aging. Ultimately, this cascade of events could trigger PD pathophysiology. The fungicide benomyl, for instance, increases PD risk by inhibiting ALDH, causing subsequent DOPAL accumulation (36). Furthermore, neuromelanin has the potential to bind environmental redoxactive metal ions in situ. These are released upon neuronal death, augmenting DOPAL-induced oligomerization of $\alpha$-synuclein $(37,38)$.

Altogether, the autotoxicity theory clarifies the selective vulnerability of central and peripheral catecholaminergic neurons, converting a stabile negative feedback-regulated in-cell system to a fragile, unstoppable positive feedback loop (33). This context naturally provides rationale for the development of biofluid markers of dopaminergic/noradrenergic origin.

\section{BIOFLUID CATECHOLAMINE MARKERS FOR PRODROMAL PD: THE EVIDENCE}

So far, only a handful of researchers investigated the biomarker potential of circulating catecholamines or derivatives in prodromal or de novo PD (dnPD), evidently with no record of present or past therapy with anti-parkinsonian drugs (Table 1). For matters of comparison, neurochemical investigations in early-stage PD patients have also been enlisted in the table.

Kienzl et al. (39) included 16 dnPD patients with Hoehn and Yahr stage scores I or II. The study of D'Andrea and colleagues included $16 \mathrm{dnPD}$ patients diagnosed within 1 year or less following the onset of parkinsonism (40). In 2019, the same group analyzed a larger variety of catecholamines and trace amines, with inclusion of $21 \mathrm{dnPD}$ patients with a disease duration of less than 2 years (47). As for Goldstein et al. (41), 14 out of 34 PD patients were $\operatorname{dnPD}$, with cerebrospinal fluid (CSF) obtained within 2 years or even before the onset of parkinsonism. The authors also excluded DA data from 17 PD patients to eliminate potential treatment effects, even after levodopa washout. Next, the same group performed similar research in early-stage PD patients, complying with three out of four clinical PD criteria, that were off levodopa or MAO inhibitor treatments, as confirmed by 
TABLE 1 | Enlistment of studies evaluating biofluid catecholamines and their derivatives or precursors as potential markers for prodromal, de novo, or early-stage Parkinson's disease.

\begin{tabular}{|c|c|c|c|c|}
\hline Study & Subjects (N) & CA marker & Main findings & Remarks \\
\hline Kienzl et al. (39) & $\begin{array}{l}15 \mathrm{HC} \\
16 \mathrm{dnPD} \\
21 \mathrm{PD} \\
11 \text { OTHER }\end{array}$ & $\begin{array}{l}\text { Urinary DA-3-o-sulfate } \\
\text { and DA-4-o-sulfate }\end{array}$ & $\begin{array}{l}\text { DA-4-o-sulfate is reduced in dnPD compared } \\
\text { to } \mathrm{HC} \text { and OTHER }\end{array}$ & $\begin{array}{l}\text { DA-4-o-sulfate levels remained } \\
\text { unaltered during levodopa therapy }\end{array}$ \\
\hline D'Andrea et al. (40) & $\begin{array}{l}28 \mathrm{HC} \\
16 \mathrm{dnPD} \\
47 \mathrm{nfPD} \\
21 \mathrm{fPD}\end{array}$ & $\begin{array}{l}\text { Plasma octopamine } \\
\text { and NA }\end{array}$ & $\begin{array}{l}\text { Octopamine levels were lower in dn/nf/fPD vs. } \\
\mathrm{HC} \text {; NA levels were only lower in nf/fPD vs. HC }\end{array}$ & $\begin{array}{l}\text { Trace amines are hard to detect; very } \\
\text { low circulating levels }\end{array}$ \\
\hline Goldstein et al. (41) & $\begin{array}{l}38 \mathrm{HC} \\
34 \mathrm{PD}(14 \mathrm{dn}) \\
54 \mathrm{MSA} \\
20 \mathrm{PAF}\end{array}$ & $\begin{array}{l}\text { Plasma and CSF } \\
\text { I-DOPA, DA, DOPAC, } \\
\text { NE and DHPG }\end{array}$ & $\begin{array}{l}\text { CSF DOPAC and DHPG strongly decreased in } \\
\text { all groups vs. HC; CSF DOPAC lower, and CSF } \\
\text { DHPG higher, in PD than PAF; CSF DOPAC } \\
100 \% \text { sensitive and } 89 \% \text { specific in dnPD vs. } \\
\text { HC }\end{array}$ & $\begin{array}{l}\text { Plasma DHPG levels were lower in } \\
\text { PAF than in HC; in PD, CSF and } \\
\text { plasma DHPG were positively } \\
\text { correlated }\end{array}$ \\
\hline Goldstein et al. (42) & $\begin{array}{l}26 \mathrm{HC} \\
12 \mathrm{PD}+\mathrm{OH} \\
11 \mathrm{PD}-\mathrm{OH} \\
21 \mathrm{MSA}-\mathrm{p} \\
5 \mathrm{MSA}-\mathrm{c} \\
11 \mathrm{PAF}\end{array}$ & $\begin{array}{l}\text { Plasma } \\
\text { F-DOPAC and } \\
\text { DHPG }\end{array}$ & $\begin{array}{l}\text { F-DOPAC levels were higher, and, DHPG levels } \\
\text { lower, in PD+OH vs. MSA-p and HC }\end{array}$ & $\begin{array}{l}\text { F-DOPAC:DHPG ratio differentiated } \\
\text { PD+OH from MSA-p }\end{array}$ \\
\hline Goldstein et al. (43) & $\begin{array}{l}32 \text { HC } \\
24 \text { PD } \\
32 \text { MSA-p } \\
18 \text { PAF }\end{array}$ & $\begin{array}{l}\text { CSF (cys-)l-DOPA, } \\
\text { (cys-) DA, DOPAC, } \\
\text { (N)A, DHPG }\end{array}$ & $\begin{array}{l}\text { DOPAC was decreased in PD and MSA-p vs. } \\
\mathrm{HC}\end{array}$ & $\begin{array}{l}\text { cys-DA:DOPAC two times as high in } \\
\text { PD and MSA-p than HC or PAF }\end{array}$ \\
\hline Figura et al. (44) & $\begin{array}{l}22 \text { early PD } \\
28 \text { aPD+LID } \\
23 \text { aPD-LID }\end{array}$ & $\begin{array}{l}\text { Serum phenylalanine } \\
\text { and tyrosine }\end{array}$ & $\begin{array}{l}\text { Phenylalanine levels were higher in early PD } \\
\text { than aPD+LID }\end{array}$ & $\begin{array}{l}\text { No differences in tyrosine; no } \\
\text { inclusion of } \mathrm{HC}\end{array}$ \\
\hline Goldstein et al. (45) & $\begin{array}{l}26 \text { subjects at risk for } \\
\text { PD with } 3.7 \text { years FU }\end{array}$ & $\begin{array}{l}\text { CSF I-DOPA and } \\
\text { DOPAC }\end{array}$ & $\begin{array}{l}4 \text { out of } 26 \text { with low baseline I-DOPA and } \\
\text { DOPAC developed PD }\end{array}$ & $\begin{array}{l}\text { At least three risk factors: genetic, } \\
\text { olfactory, } \mathrm{RBD} \text {, and/or } \mathrm{OH}\end{array}$ \\
\hline Kim et al. (46) & $\begin{array}{l}26 \text { untreated dnPD } \\
\text { with } \pm 2.5 \text { years of } \\
\text { disease duration }\end{array}$ & $\begin{array}{l}\text { Tear fluid DA, NA and A } \\
\text { levels }\end{array}$ & $\begin{array}{l}\text { NA and DA were increased, A decreased, in } \\
\text { PD vs. HC; increases were pronounced on the } \\
\text { ipsilateral motor side }\end{array}$ & $\begin{array}{l}\text { Results were confirmed in (pre)clinical } \\
\text { stages of a neurotoxic PD mouse } \\
\text { model }\end{array}$ \\
\hline D'Andrea et al. (47) & $\begin{array}{l}10 \mathrm{HC} \\
21 \mathrm{dnPD} \\
27 \text { PD-treat }\end{array}$ & $\begin{array}{l}\text { Plasma tyrosine, } \\
\text { tyramine, tryptamine, } \\
\text { octopamine, TRP, } \\
\beta \text {-PEA, 5-HT, NA, MNE }\end{array}$ & $\begin{array}{l}\text { Tyramine differed between all three groups; } \\
\text { tyramine, tyrosine and NA combined acted as } \\
\text { biomarkers of disease progression }\end{array}$ & $\begin{array}{l}\text { Trace amines are hard to detect; very } \\
\text { low circulating levels }\end{array}$ \\
\hline
\end{tabular}

B-PEA, beta phenylethylamine; 5-HT, serotonin (5-hydroxytryptamine); A, adrenaline; aPD+/-LID, advanced PD patients with(out) levodopa-induced dyskinesia; CA, catecholamine; CSF, cerebrospinal fluid; cys-DA, cysteinyl-dopamine; cys-I-DOPA, cysteinyl-levodopa; DA, dopamine; DHPG, 3,4-dihydroxyphenylglycol; dnPD, de novo PD subjects; DOPAC, 3,4-dihydroxyphenylacetic acid; F-DOPAC, fluoro-DOPAC; fPD, fluctuating PD patients; FU, follow-up; HC, healthy controls; I-DOPA, levodopa (3,4-dihydroxyphenylalanine); MNE, metanephrine; MSA, multiple system atrophy; MSA-c, cerebellar variant of MSA; MSA-p, parkinsonian variant of MSA; NA, noradrenaline; nfPD, non-fluctuating PD patients; OH,

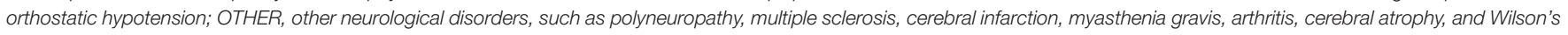
disease; PAF, pure autonomic failure; PD, Parkinson's disease; PD-treat, PD patients on levodopa or other dopaminergic drugs; RBD, REM sleep behavior disorder; TRP, tryptophan.

additionally measured CSF DOPA levels (42, 43). Figura et al. examined serum amino acids in four dnPD and 18 early PD subjects. The latter group was defined as having a score of I or II on the Hoehn and Yahr staging scale, less than 3 years of disease duration, and stable levodopa response (44). Goldstein et al. (45) also clinically evaluated 26 prodromal subjects who had at least three risk factors for PD, i.e., olfactory dysfunction, RBD, $\mathrm{OH}$, and/or genetic predisposition, and, no motor symptoms. Finally, Kim et al. (46) assessed tear fluid catecholamines in 26 untreated dnPD patients having Hoehn and Yahr stages I-II.

At first glance, (i) three CSF and plasma metabolites [DOPAC (41, 43, 45), DHPG (41, 42), L-DOPA $(41,43,45)]$, (ii) one plasma and three tear fluid catecholamines $[\mathrm{N}(\mathrm{A})(40,41,46)$, DA (46)], and (iii) two derivative plasma trace amines [tyramine
(47) and octopamine (40), whether or not combined with plasma NA (47)] seem promising as markers for prodromal or dnPD (Table 1). Regarding CSF DOPAC, results are quite unequivocal, with very low to low levels across PD stages, from prodromal (45) to de novo (41) and early-stage (43). For instance, four out of 26 subjects at risk for PD with low CSF levels of DOPAC $(<1.22$ $\mathrm{pmol} / \mathrm{ml})$ and $\mathrm{L}-\mathrm{DOPA}(<2.63 \mathrm{pmol} / \mathrm{ml})$ at baseline inclusion eventually developed PD (45).

Just like DHPG, MHPG-the final metabolite of NA metabolism-has also been indicated as a potential biofluid marker for Lewy body diseases, albeit in the context of cognitive dysfunction in PD (48), or to differentiate DLB from AD (49). Because MHPG crosses both blood-brain (BBB) and CSF-blood barriers (50), plasma alterations may well be indicative of central noradrenergic dysfunction. 


\section{EXTRACELLULAR VESICLES AS A NOVEL DIAGNOSTIC AND THERAPEUTIC APPROACH}

It is still challenging to efficiently treat $\mathrm{PD}$ patients, due to a BBB impeding passage of most drugs. The development of various drug delivery systems encapsulating, e.g., DA, is, therefore, desirable (51). The focus herein lies upon extracellular vesicles (EVs), nanoparticles including exosomes $(<100 \mathrm{~nm})$, microvesicles $(100-1,000 \mathrm{~nm})$, and apoptotic bodies (up to $4,000 \mathrm{~nm}$ ) (52). Their cargo mostly contains lipids, proteins, mRNA, and microRNA (miRNA). EVs show low immunogenicity and can easily cross the BBB. As such, smallmolecule therapeutics like paclitaxel, doxorubicin, and curcumin have been encapsulated into exosomes to treat cancer and inflammatory diseases (53-55).

One great advantage over levodopa of an exosomal DA delivery system to the brain via a peripheral route would be that exosomes can be engineered to strategically target specific neurons or neuronal populations (56). This would prevent the non-targeted levodopa-derived DA exocytosis in serotonergic rather than residual dopaminergic nerve terminals. These serotonergic projections innervate entirely different systems, such as the prefrontal cortex, nucleus accumbens, subthalamic nucleus, and hippocampus (57). Since VMAT2 is contained in serotonergic neurons too for the uptake of in situ synthesized DA, increased extracellular DA levels in these extrastriatal regions have been linked to various (non-)motor symptoms, such as psychosis and LID (58).

On the other hand, exosomes may intercellularly transfer and sequester misfolded, pathogenic $\alpha$-synuclein from neuron to neuron and from neuron to glia, in turn leading to the activation of an inflammatory response, and thus contributing to neuronal dysfunction and overall disease progression (59). However, few studies also reported functional evidence of a neuroprotective functionality via exosomal externalization of $\alpha$-synuclein, which may be beneficial for the surviving dopaminergic neurons of the $\operatorname{SNpc}(60,61)$.

Despite the potential role of EVs in contributing to the onset or progression of $\mathrm{PD}$, exosomes could represent a valuable drug delivery tool (62). Qu et al. (63) administered DA-loaded blood exosomes to PD mice, which successfully entered the nigrostriatal system, induced nigral dopaminergic neurogenesis, and improved the symptomatic performance compared to exogenous DA treatment (64). More recently, Narbute et al. (65) developed EVs derived from stem cells from the dental pulp of human exfoliated deciduous teeth, which are highly proliferative and capable of differentiating into, e.g., neural cells (66-68). These derived EVs were administered intranasally and improved gait parameters in a PD rat model (65).

Furthermore, EVs contain miRNA-124a as part of their cargo (69), which is a potent regulator of MAO-A expression in dopaminergic neurons (70). Regulating EV-containing miRNA124a expression levels in the brain might be an inventive therapeutic approach, especially because it avoids adverse effects caused by conventional MAO-A inhibitors. Meanwhile, Gui et al.
(71) found 16 downregulated miRNAs in CSF exosomes of PD patients compared to controls. Cao et al. (72) concluded that miRNA-19b was downregulated and miRNA-195 and miRNA-24 upregulated in PD. This raises the possibility that serum exosomal miRNA profiling may be a novel strategy for diagnosing prodromal PD.

\section{CONCLUSIONS AND FUTURE PERSPECTIVES}

By and large, in PD, $\alpha$-synuclein pathologically spreads in synergy with central and peripheral catecholaminergic dysfunctioning, so the quest for biofluid catecholamine markers seems a rational choice. Above, we provided neurochemical, clinical, and pathophysiolocial evidence. On the systemic level, the threshold theory acknowledges that the earliest symptoms are caused by catecholaminergic deficiency of the peripheral/autonomic nervous system, followed by a central dopaminergic depletion. On the cellular level, the hypothesis of DOPAL- and DOPEGALinduced synucleinopathy and a consequentially altered metabolic route of DA and NA are in agreement with a handful of studies so far that indicated CSF DOPAC and plasma DHPG/MHPG to be of potential interest as biomarkers for prodromal PD in particular. Moreover, the concept of EVs in CSF/plasma needs further refinement, since these nanoparticles may contain a vast amount of information about disease progression, for instance as encoded by exosomal miRNA profiles.

Preferentially, future studies should include more PD patients in prodromal and de novo stages based on strict inclusion criteria [e.g., risk factors (45)] and with prolonged followup, since current studies only comprised a mere 10-30 study subjects per group. Baseline and intermittent sampling with preceding levodopa washouts would be necessary if early-stage PD subjects are to be included or if treatment was initiated in the meanwhile. Additionally, optimal cutoff CSF/plasma values of DOPAC, L-DOPA, and DHPG/MHPG need to be determined and independently verified on an international scale. In this regard, "very low, low, normal, or high" levels can be attributed to numerical meanings. Metabolomic approaches, such as liquid chromatography with sensitive electrochemical detection, whether or not coupled to mass spectrometry, are routinely implemented in most research hospitals and are feasible techniques for catecholamine biomarker analyses in daily clinical practice (73). Finally, one should also reckon with important methodological issues that are inherent in monoaminergic research, such as sampling conditions (e.g., CSF rostrocaudal concentration gradient, circadian rhythm (74), and dietary effects) and pre-analytical stability of CSF catecholamine metabolites (75).

\section{AUTHOR CONTRIBUTIONS}

Conceptualization, design, figure, and table: YV. Drafting of original manuscript: YV and YH. Critical manuscript revision and editing: IM and PD. Approval of final version: YV, YH, IM, 
and PD. Funding acquisition: YV, IM, and PD. All authors agree to be accountable for all aspects with regard to this work.

\section{FUNDING}

The authors gratefully acknowledge the funding support of the Belgian Alzheimer Research Foundation-Stichting Alzheimer Onderzoek (SAO-FRA grant \#2018/0027) and Alzheimer Nederland (project no. WE.03-2019-11). This work was further supported by the collaborative agreement

\section{REFERENCES}

1. Kalia LV, Lang AE. Parkinson's disease. Lancet. (2015) 386:896912. doi: 10.1016/S0140-6736(14)61393-3

2. Van Den Eeden SK, Tanner CM, Bernstein AL, Fross RD, Leimpeter A, Bloch $\mathrm{DA}$, et al. Incidence of Parkinson's disease: variation by age, gender, and race/ethnicity. Am J Epidemiol. (2003) 157:1015-22. doi: 10.1093/aje/kwg068

3. Rees RN, Noyce AJ, Schrag A. The prodromes of Parkinson's disease. Eur J Neurosci. (2019) 49:320-7. doi: 10.1111/ejn.14269

4. Ehringer H, Hornykiewicz O. Distribution of noradrenaline and dopamine (3-hydroxytyramine) in the human brain and their behavior in diseases of the extrapyramidal system. Wien Klin Wochenschr. (1960) 38:1236-39.

5. Cotzias GC. Levodopa in the treatment of Parkinsonism. JAMA. (1971) 218:1903-8. doi: 10.1001/jama.1971.03190260019005

6. Goldstein DS. Catecholamines 101. Clin Auton Res. (2010) 20:33152. doi: 10.1007/s10286-010-0065-7

7. Isaias IU, Marotta G, Pezzoli G, Sabri O, Schwarz J, Crenna P, et al. Enhanced catecholamine transporter binding in the locus coeruleus of patients with early Parkinson disease. BMC Neurol. (2011) 11:88. doi: 10.1186/1471-2377-11-88

8. Goldstein DS, Sullivan P, Holmes C, Miller GW, Sharabi Y, Kopin IJ. A vesicular sequestration to oxidative deamination shift in myocardial sympathetic nerves in Parkinson's disease. J Neurochem. (2014) 131:21928. doi: $10.1111 /$ jnc. 12766

9. Goldstein DS, Sharabi Y. The heart of PD: lewy body diseases as neurocardiologic disorders. Brain Res. (2019) 1702:7484. doi: 10.1016/j.brainres.2017.09.033

10. Braak H, Del Tredici K, Rüb U, de Vos RA, Jansen Steur EN, Braak E. Staging of brain pathology related to sporadic Parkinson's disease. Neurobiol Aging. (2003) 24:197-211. doi: 10.1016/S0197-4580(02)00065-9

11. Del Tredici K, Braak H. Lewy pathology and neurodegeneration in premotor Parkinson's disease. Mov Disord. (2012) 27:597-607. doi: 10.1002/mds.24921

12. Machado BH, Brody MJ. Role of the nucleus ambiguus in the regulation of heart rate and arterial pressure. Hypertension. (1988) 11:602-7. doi: 10.1161/01.HYP.11.6.602

13. Kim JS, Shim Y-S, Song I-K, Yoo J-Y, Kim H-T, Kim Y-I, et al. Cardiac sympathetic denervation and its association with cognitive deficits in Parkinson's disease. Parkinsonism Relat Disord. (2009) 15:706-8. doi: 10.1016/j.parkreldis.2009.01.008

14. Nakamura T, Hirayama M, Yasmashita F, Uchida K, Hama T, Watanabe H, et al. Lowered cardiac sympathetic nerve performance in response to exercise in Parkinson's disease. Mov Disord. (2010) 25:1183-9. doi: 10.1002/mds.23127

15. Nakamura T, Hirayama M, Hara T, Hama T, Watanabe H, Sobue G. Does cardiovascular autonomic dysfunction contribute to fatigue in Parkinson's disease? Mov Disord. (2011) 26:1869-74. doi: 10.1002/mds.23744

16. Goldstein DS, Holmes C, Bentho O, Sato T, Moak J, Sharabi Y, et al. Biomarkers to detect central dopamine deficiency and distinguish Parkinson disease from multiple system atrophy. Parkinsonism Relat Disord. (2008) 14:600-7. doi: 10.1016/j.parkreldis.2008.01.010

17. Kim JS, Park HE, Oh YS, Lee SH, Park JW, Son BC, et al. Orthostatic hypotension and cardiac sympathetic denervation in Parkinson disease patients with REM sleep behavioral disorder. J Neurol Sci. (2016) 15:5963. doi: 10.1016/j.jns.2016.01.020 between the Flemish Institute for Technological Research (VITO) and the Research Foundation Flanders (FWO), of which YV is a senior postdoctoral research fellow (VITOFWO \#12Z1620N). Funding was also provided by the Joint Programming Initiative Neurodegenerative Diseases (JPND) multinational research project HEROES (ZonMw project \#733051072), the Institute Born-Bunge (IBB), the Medical Research Foundation Antwerp, the Thomas Riellaerts research fund, Neurosearch Antwerp, and the Alzheimer Center of the University Medical Center Groningen.
18. Oka H, Yoshioka M, Onouchi K, Morita M, Mochio S, Suzuki M, et al. Impaired cardiovascular autonomic function in Parkinson's disease with visual hallucinations. Mov Disord. (2007) 22:1510-4. doi: 10.1002/mds.21581

19. Romagnolo A, Zibetti M, Merola A, Canova D, Sarchioto M, Montanaro E, et al. Cardiovascular autonomic neuropathy and falls in Parkinson disease: a prospective cohort study. J Neurol. (2019) 266:85-91. doi: 10.1007/s00415-018-9104-4

20. Goldstein DS, Holmes C, Sharabi Y, Wu T. Survival in synucleinopathies: a prospective cohort study. Neurology. (2015) 85:1554-61. doi: 10.1212/WNL.0000000000002086

21. Edwards LL, Pfeiffer RF, Quigley EMM, Hofman R, Balluff $M$. Gastrointestinal symptoms in Parkinson's disease. Mov Disord. (1991) 6:151-6. doi: 10.1002/mds.870060211

22. Goldstein DS, Holmes CS, Dendi R, Bruce SR, Li S-T. Orthostatic hypotension from sympathetic denervation in Parkinson's disease. Neurology. (2002) 58:1247-55. doi: 10.1212/WNL.58.8.1247

23. Ghebremedhin E, Del Tredici K, Langston JW, Braak H. Diminished tyrosine hydroxylase immunoreactivity in the cardiac conduction system and myocardium in Parkinson's disease: an anatomical study. Acta Neuropathol. (2009) 118:777-84. doi: 10.1007/s00401-009-0596-y

24. Goldstein DS, Pekker MJ, Eisenhofer G, Sharabi Y. Computational modeling reveals multiple abnormalities of myocardial noradrenergic function in lewy body diseases. JCI Insight. (2019) 4:e130441. doi: 10.1172/jci.insight.130441

25. Imrich R, Eldadah BA, Bentho O, Pechnik S, Sharabi Y, Holmes C, et al. Attenuated pre-ejection period response to tyramine in patients with cardiac sympathetic denervation. Ann N Y Acad Sci. (2008) 1148:4869. doi: 10.1196/annals.1410.066

26. Yoshita M, Taki J, Yokoyama K, Noguchi-Shinohara M, Matsumoto $\mathrm{Y}$, Nakajima $\mathrm{K}$, et al. Value of 123I-MIBG radioactivity in the differential diagnosis of DLB from AD. Neurology. (2006) 66:1850-4. doi: 10.1212/01.wnl.0000219640.59984.a7

27. Goldstein DS, Sewell L, Sharabi Y. Autonomic dysfunction in PD: a window to early detection? J Neurol Sci. (2011) 310:118-22. doi: 10.1016/j.jns.2011.04.011

28. Visanji NP, Brooks PL, Hazrati LN, Lang AE. The prion hypothesis in Parkinson's disease: braak to the future. Acta Neuropathol Commun. (2013) 1:2. doi: 10.1186/2051-5960-1-2

29. Engelender S, Isacson O. The threshold theory for Parkinson's disease. Trends Neurosci. (2017) 40:4-14. doi: 10.1016/j.tins.2016.10.008

30. Tysnes O-B, Kenborg L, Herlofson K, Steding-Jessen M, Horn A, Olsen JH, et al. Does vagotomy reduce the risk of Parkinson's disease? Ann Neurol. (2015) 78:1011-2. doi: 10.1002/ana.24531

31. Svensson E, Horváth-Puhó E, Thomsen RW, Djurhuus JC, Pedersen L, Borghammer P, et al. Vagotomy and subsequent risk of Parkinson's disease. Ann Neurol. (2015) 78:522-29. doi: 10.1002/ana.24448

32. Ross GW, Petrovitch H, Abbott RD, Nelson J, Markesbery W, David D, et al. Parkinsonian signs and substantia nigra neuron density in decendents elders without PD. Ann Neurol. (2004) 56:532-9. doi: 10.1002/ana.20226

33. Goldstein DS, Kopin IJ, Sharabi Y. Catecholamine autotoxicity. Implications for pharmacology and therapeutics of Parkinson disease and related disorders. Pharmacol Ther. (2014) 144:268-82. doi: 10.1016/j.pharmthera.2014.06.006

34. Li SW, Lin TS, Minteer S, Burke WJ. 3,4-Dihydroxyphenylacetaldehyde and hydrogen peroxide generate a hydroxyl radical: possible role in 
Parkinson's disease pathogenesis. Brain Res Mol Brain Res. (2001) 93:17. doi: 10.1016/S0169-328X(01)00120-6

35. Kang SS, Liu X, Ahn EH, Xiang J, Manfredsson FP, Yang X, et al. Norepinephrine metabolite DOPEGAL activates AEP and pathological tau aggregation in locus coeruleus. J Clin Invest. (2020) 130:42237. doi: 10.1172/JCI130513

36. Fitzmaurice AG, Rhodes SL, Lulla A, Murphy NP, Lam HA, O’Donnell $\mathrm{KC}$, et al. Aldehyde dehydrogenase inhibition as a pathogenic mechanism in Parkinson disease. Proc Natl Acad Sci USA. (2013) 110:636-41. doi: 10.1073/pnas.1220399110

37. Jinsmaa Y, Sullivan P, Gross D, Cooney A, Sharabi Y, Goldstein DS, et al. Divalent metal ions enhance DOPAL-induced oligomerization of alphasynuclein. Neurosci Lett. (2014) 569:27-32. doi: 10.1016/j.neulet.2014.03.016

38. Enochs WS, Sarna T, Zecca L, Riley PA, Swartz HM. The roles of neuromelanin, binding of metal ions, and oxidative cytotoxicity in the pathogenesis of Parkinson's disease: a hypothesis. J Neural Transm Park Dis Dement Sect. (1994) 7:83-100. doi: 10.1007/BF02260963

39. Kienzl E, Eichinger K, Sofic E, Jellinger K, Riederer P, Kuhn W, et al. Urinary dopamine sulfate: regulations and significance in neurological disorders. $J$ Neural Transm Suppl. (1990) 32:471-9. doi: 10.1007/978-3-7091-9113-2_64

40. D'Andrea G, Nordera G, Pizzolato G, Bolner A, Colavito D, Flaibani $\mathrm{R}$, et al. Trace amine metabolism in Parkinson's disease: low circulating levels of octopamine in early disease stages. Neurosci Lett. (2010) 469:34851. doi: 10.1016/j.neulet.2009.12.025

41. Goldstein DS, Holmes C, Sharabi Y. Cerebrospinal fluid biomarkers of central catecholamine deficiency in Parkinson's disease and other synucleinopathies. Brain. (2012) 135:1900-13. doi: 10.1093/brain/aws055

42. Goldstein DS, Kopin IJ, Sharabi Y, Holmes C. Plasma biomarkers of decreased vesicular storage distinguish Parkinson disease with orthostatic hypotension from the Parkinsonian form of multiple system atrophy. Clin Auton Res. (2015) 25:61-7. doi: 10.1007/s10286-015-0268-z

43. Goldstein DS, Holmes C, Sullivan P, Jinsmaa Y, Kopin IJ, Sharabi Y. Elevated cerebrospinal fluid ratios of cysteinyl-dopamine/3,4-dihydroxyphenylacetic acid in Parkinsonian synucleinopathies. Parkinsonism Relat Disord. (2016) 31:79-86. doi: 10.1016/j.parkreldis.2016.07.009

44. Figura M, Kuśmierska K, Bucior E, Szlufik S, Koziorowski D, Jamrozik Z, et al. Serum amino acid profile in patients with Parkinson's disease. PLoS ONE. (2018) 13:e0191670. doi: 10.1371/journal.pone.0191670

45. Goldstein DS, Holmes C, Lopez GJ, Wu T, Sharabi Y. Cerebrospinal fluid biomarkers of central dopamine deficiency predict Parkinson's disease. Parkinsonism Relat Disord. (2018) 50:108-12. doi: 10.1016/j.parkreldis.2018.02.023

46. Kim AR, Nodel MR, Pavlenko TA, Chesnokova NB, Yakhno NN, Ugrumov MV. Tear fluid catecholamines as biomarkers of the Parkinson's disease: a clinical and experimental study. Acta Nat. (2019) 11:99103. doi: 10.32607/20758251-2019-11-4-99-103

47. D'Andrea G, Pizzolato G, Gucciardi A, Stocchero M, Giordano G, Baraldi $E$ et al. Different circulating trace amine profiles in de novo and treated Parkinson's disease patients. Sci Rep. (2019) 9:6151. doi: 10.1038/s41598-019-42535-w

48. van der Zee S, Vermeiren Y, Fransen E, Van Dam D, Aerts T, Gerritsen $\mathrm{MJ}$, et al. Monoaminergic markers across the cognitive spectrum of Lewy body disease. J Parkinsons Dis. (2018) 8:71-84. doi: 10.3233/JPD171228

49. Janssens J, Vermeiren Y, Fransen E, Aerts T, Van Dam D, Engelborghs S, et al. Cerebrospinal fluid and serum MHPG improve Alzheimer's disease versus dementia with lewy bodies differential diagnosis. Alzheimers Dement (Amst). (2018) 10:172-81. doi: 10.1016/j.dadm.2018.01.002

50. Sharma RP, Javaid JI, Faull K, Davis JM, Janicak PG. CSF and plasma MHPG, and CSF MHPG index: pretreatment levels in diagnostic groups and response to somatic treatments. Psychiatry Res. (1994) 51:51-60. doi: 10.1016/0165-1781(94)90046-9

51. Gunay MS, Ozer AY, Chalon S. Drug delivery systems for imaging and therapy of Parkinson's disease. Curr Neuropharmacol. (2016) 4:37691. doi: 10.2174/1570159X14666151230124904

52. Gyorgy B, Szabo TG, Pasztoi M, Pal Z, Misjak P, Aradi B, et al. Membrane vesicles, current state-of-the-art: emerging role of extracellular vesicles. Cell Mol Life Sci. (2011) 16:2667-88. doi: 10.1007/s00018-011-0689-3
53. Sun D, Zhuang X, Xiang X, Liu Y, Zhang S, Liu C, et al. A novel nanoparticle drug delivery system: the anti-inflammatory activity of curcumin is enhanced when encapsulated in exosomes. Mol Ther. (2010) 9:160614. doi: $10.1038 / \mathrm{mt} .2010 .105$

54. Tian Y, Li S, Song J, Ji T, Zhu M, Anderson GJ, et al. A doxorubicin delivery platform using engineered natural membrane vesicle exosomes for targeted tumor therapy. Biomaterials. (2014) 7:2383-90. doi: 10.1016/j.biomaterials.2013.11.083

55. Kim MS, Haney MJ, Zhao Y, Mahajan V, Deygen I, Klyachko NL, et al. Development of exosome-encapsulated paclitaxel to overcome MDR in cancer cells. Nanomedicine. (2016) 3:655-64. doi: 10.1016/j.nano.2015.10.012

56. Wu X, Zheng T, Zhang B. Exosomes in Parkinson's disease. Neurosci Bull. (2017) 33:331-8. doi: 10.1007/s12264-016-0092-Z

57. De Deurwaerdère P, Di Giovanni G. Serotonergic modulation of the activity of mesencephalic dopaminergic systems: therapeutic implications. Prog Neurobiol. (2017) 151:175-236. doi: 10.1016/j.pneurobio.2016.03.004

58. Navailles $S$, De Deurwaerdère $P$. Imbalanced dopaminergic transmission mediated by serotonergic neurons in L-DOPA-induced dyskinesia. Parkinsons Dis. (2012) 2012:323686. doi: 10.1155/2012/323686

59. Russo I, Bubacco L, Greggio E. Exosomes-associated neurodegeneration and progression of Parkinson's disease. Am J Neurodegener Dis. (2012) 1:217-25.

60. Ramirez A, Heimbach A, Grundemann J, Stiller B, Hampshire D, Cid LP, et al. Hereditary parkinsonism with dementia is caused by mutations in ATP13A2, encoding a lysosomal type 5 P-type ATPase. Nat Genet. (2006) 38:1184-91. doi: 10.1038/ng1884

61. Ramonet D, Podhajska A, Stafa K, Sonnay S, Trancikova A, Tsika E, et al. PARK9-associated ATP13A2 localizes to intracellular acidic vesicles and regulates cation homeostasis and neuronal integrity. Hum Mol Genet. (2012) 21:1725-43. doi: $10.1093 / \mathrm{hmg} / \mathrm{ddr} 606$

62. Porro C, Panaro MA, Lofrumento DD, Hasalla E, Trotta T. The multiple roles of exosomes in Parkinson's disease: an overview. Immunopharmacol Immunotoxicol. (2019) 4:469-76. doi: 10.1080/08923973.2019.1650371

63. Qu M, Lin Q, Huang L, Fu Y, Wang L, He S, et al. Dopamine-loaded blood exosomes targeted to brain for better treatment of Parkinson's disease. $J$ Control Release. (2018) 287:156-66. doi: 10.1016/j.jconrel.2018.08.035

64. Borta A, Hoglinger GU. Dopamine and adult neurogenesis. J Neurochem. (2007) 3:587-95. doi: 10.1111/j.1471-4159.2006.04241.x

65. Narbute K, Pilipenko V, Pupure J, Dzirkale Z, Jonavice U, Tunaitis V, et al. Intranasal administration of extracellular vesicles derived from human teeth stem cells improves motor symptoms and normalizes tyrosine hydroxylase expression in the substantia nigra and striatum of the 6-hydroxydopaminetreated rats. Stem Cells Transl Med. (2019) 5:490-9. doi: 10.1002/sctm.18-0162

66. Miura M, Gronthos S, Zhao M, Lu B, Fisher LW, Robey PG, et al. SHED: stem cells from human exfoliated deciduous teeth. Proc Natl Acad Sci USA. (2003) 10:5807-12. doi: 10.1073/pnas.0937635100

67. Sakai K, Yamamoto A, Matsubara K, Nakamura S, Naruse M, Yamagata M, et al. Human dental pulp-derived stem cells promote locomotor recovery after complete transection of the rat spinal cord by multiple neuro-regenerative mechanisms. J Clin Invest. (2012) 1:80-90. doi: 10.1172/JCI59251

68. Jarmalaviciute A, Tunaitis V, Strainiene E, Aldonyte R, Ramanavicius A, Venalis A, et al. A new experimental model for neuronal and glial differentiation using stem cells derived from human exfoliated deciduous teeth. J Mol Neurosci. (2013) 51:307-17. doi: 10.1007/s12031-0130046-0

69. Karnati HK, Garcia JH, Tweedie D, Becker RE, Kapogiannis D, Greig NH. Neuronal enriched extracellular vesicle proteins as biomarkers for traumatic brain injury. J Neurotrauma. (2019) 36:975-87. doi: 10.1089/neu.2018.5898

70. Higuchi Y, Soga T, Parhar IS. Potential roles of microRNAs in the regulation of monoamine oxidase A in the brain. Front Mol Neurosci. (2018) 11:339. doi: $10.3389 /$ fnmol.2018.00339

71. Gui Y, Liu H, Zhang L, Lv W, Hu X. Altered microRNA profiles in cerebrospinal fluid exosome in Parkinson disease and Alzheimer disease. Oncotarget. (2015) 6:37043-53. doi: 10.18632/oncotarget.6158

72. Cao XY, Lu JM, Zhao ZQ, Li MC, Lu T, An XS, et al. MicroRNA biomarkers of Parkinson's disease in serum exosome-like microvesicles. Neurosci Lett. (2017) 644:94-9. doi: 10.1016/j.neulet.2017.02.045

73. Havelund JF, Heegaard NHH, Færgeman NJK, Gramsbergen JB. Biomarker research in Parkinson's disease using metabolite 
profiling. Metabolites. (2017) 7:e42. doi: 10.3390/metabo70 30042

74. Janssens J, Atmosoerodjo SD, Vermeiren Y, Absalom AR, den Daas I, De Deyn PP. Sampling issues of cerebrospinal fluid and plasma monoamines: investigation of the circadian rhythm and rostrocaudal concentration gradient. Neurochem Int. (2019) 128:154-62. doi: 10.1016/j.neuint.2019.04.015

75. Willemse EAJ, Vermeiren Y, Garcia-Ayllon MS, Bridel C, De Deyn PP, Engelborghs S, et al. Pre-analytical stability of novel cerebrospinal fluid biomarkers. Clin Chim Acta. (2019) 497:204-11. doi: 10.1016/j.cca.2019.07.024
Conflict of Interest: The authors declare that the research was conducted in the absence of any commercial or financial relationships that could be construed as a potential conflict of interest.

Copyright $\odot 2020$ Vermeiren, Hirschberg, Mertens and De Deyn. This is an openaccess article distributed under the terms of the Creative Commons Attribution License (CC BY). The use, distribution or reproduction in other forums is permitted, provided the original author(s) and the copyright owner(s) are credited and that the original publication in this journal is cited, in accordance with accepted academic practice. No use, distribution or reproduction is permitted which does not comply with these terms. 